\title{
The precarious balance between 'supply' and 'demand' for health care: The increasing global demand for rehabilitation service for individuals living with chronic obstructive pulmonary disease
}

\author{
Michel D Landry' \\ Elham Hamdan ${ }^{2}$ \\ Sabriya Al Mazeedi ${ }^{3}$ \\ Dina Brooks ${ }^{4}$
}

'Assistant Professor, Department of Physical Therapy at the University of Toronto (Canada), and holds a Career Scientist Award from the Ontario Ministry of Health and Long Term Care; ${ }^{2}$ Medical Director and Senior Research Fellow, Fawzia Sultan Rehabilitation Institute (Kuwait); ${ }^{3}$ Physical Therapist and Senior Research Fellow, Fawzia Sultan Rehabilitation Institute (Kuwait); ${ }^{4}$ Associate Professor, Department of Physical Therapy at the University of Toronto (Canada), and holds a Canada Research Chair in Rehabilitation for Chronic Obstructive Pulmonary Disease

Correspondence: Michel D Landry Department of Physical Therapy, University of Toronto, 160-500 University Avenue, Toronto, Ontario, M5G IV7, Canada

Tel + I 4169468560

Fax + I 4169468562

Email mike.landry@utoronto.ca

\begin{abstract}
Chronic obstructive pulmonary disease (COPD) is becoming a critical health concern that affects people living in high-, middle-, and low-income countries. Pulmonary rehabilitation (PR) has been demonstrated to be a clinical and cost-effective approach to minimizing the effects of COPD. Despite global predictions of an increased incidence of COPD, there continues to be an important misalignment between the demand and the supply of PR services. In other words, only a small proportion of individuals with COPD who require, or would benefit from, PR programs are receiving them on the global stage. This issue may be even more pronounced in middle- and low-income countries where the burden of disease is reported to be highest, and where access to health services and trained health professionals appears be to lowest. Given this predicament, we suggest that PR services must be viewed as an effective way in which to generate clinical efficiencies within health systems, and has the potential to relieve pressure on acute care systems. Although implementing PR programs require commitment and financial investment, we argue that such investments would yield important social and aggregated financial cost savings in the long term.
\end{abstract}

Keywords: global health, supply, demand, rehabilitation, health reform

Chronic obstructive pulmonary disease (COPD) is a critical global health concern affecting an increasing proportion of people living in high, middle, and low-income countries. COPD is a progressive respiratory disorder characterized by partially reversible airway obstruction and lung hyperinflation conditions that present alongside systemic manifestations (Chapman et al 2003; Yohannes and Connolly 2004; APCOPD 2005; Ait-Khaled et al 2007; Mannino and Braman 2007; Taticioglu 2007; Zhong et al 2007). It has been suggested that by the year 2020, COPD will surpass cancer and cardiac disease to become the third leading cause of death worldwide (Firlei et al 2007). The emerging global importance of COPD, and the complex implication of such increasing prevalence rates at the micro- (ie, client), meso- (ie, institution), and macro (ie, country) levels, has been highlighted by others such as Barr and colleagues (2005), Viegi and colleagues (2007), and Brooks and colleagues (2007). Overall, the evidence seems to suggest that variables such as an ageing population, high rates of tobacco use, and limited access to health services are key drivers of the global prevalence of COPD. Moreover, as suggested by others, COPD and related pulmonary diseases may become important in low-income countries where prevalence rates are rapidly increasing and where the overall burden is the greatest (Bousquet et al 2003; Chan-Yeung et al 2004a, 2004b; Ait-Khaled et al 2007). 
The neoclassical economic viewpoint posits that demand (the amount of services that are deemed medically necessary) and supply (the amount of financial or human resources available) are in 'equilibrium' when demand is fully aligned with available supply (Friedman and Elixhauser 1995; Chernew 2001). Alternatively, the so-called 'market' is deemed to be in a state of disequilibrium when demand is higher (or at times lower) than supply. A proxy measure that has been established to measure the extent to which a health care market is in alignment is wait time. In other words, short wait times signal some degree of alignment, and long wait times indicates disequilibrium between demand and supply (Landry et al 2007, 2008). Health care is infinitely complex, and does not necessarily follow such predictable and established dynamics; nonetheless, applying a neoclassical understanding of market composition within context of COPD can be instructive in establishing the degree to which demand and supply are aligned. The literature seems to indicate that, from a macro-level perspective, demand for health services for COPD has risen sharply, that the health care supply chain infrastructure (or supply) has not kept pace, and that without addressing this disequilibrium a crisis in access to services for COPD will ensue (Varkey 2004; Cao et al 2006; Ninot et al 2006; Wilkinson and Wedzicha 2006; Wilson 2006; Crockett and Price 2007; Han et al 2007).

Demand for health services are 'insatiable,' and that increasing financial and human resources can address shortterm demand, which in turn engender increase in public expectation and over-utilization of such services. Financial allocation for health services tends to occur in an environment of economic scarcity in all settings; in other words, there are rarely sufficient resources to allocate across all conditions and settings. This complex economic reality makes increasing supply somewhat less sustainable and possibly irrelevant in some resource-poor countries. Alternatively, strategies that reduce demand can create some degree of alignment between existing supply and demand, and is arguably more promising than adding more financial resource to meet demand. For instance, we have reported elsewhere that the application rehabilitation services for individuals living with COPD and other conditions has the potential to act as a mediating factor to modulate long term health service demand of more costly and resource-intensive health services (Landry et al 2008). Although further empirical evidence is required, there is a growing knowledge base that indicates that the introduction of rehabilitation early and throughout a disease process can yield positive clinical and social outcomes (Carli and Zavorsky 2005; Marcinkowski et al 2005; Prouty et al 2006).
Pulmonary rehabilitation (PR) is a multidisciplinary program that integrates components of exercise training, education, nutritional therapy, psychological support, and promotes self-management (ATS/ERS 2002; O'Donnell et al 2003; Fabbri et al 2007). There are numerous benefits of PR, including: improved health-related quality of life, improved exercise capacity, decreased perception of dyspnea, reduced admissions and days in hospital, and reduced anxiety and depression (Lacasse et al 2006; Fabbri et al 2007). PR therefore offers the potential to improve clinical outcomes and reduce aggregated direct and indirect costs associated with COPD (Faulkner and Hilleman 2002; Gadoury et al 2005). Although the introduction of PR programs require some degree of up-front financial and human resource investments; it can also be argued that the long-term cost savings that may be realized by offsetting the demand for more expensive services. Despite this argument, there is disequilibrium between demand and supply of PR services for people living with COPD. According to the Canadian Institutes for Health Information, only $2.8 \%$ of Canadians who would benefit from PR programs receive these services, and that on average clients with pulmonary conditions have a wait time of 6 days for inpatient rehabilitation services (CIHI 2005). Similarly, results from a 1998 survey of PR programs across North America, Europe, and Japan indicated that programs were available at only $56 \%$ of hospitals (Kida et al 1998). Overall, it appears that rehabilitation programs and services for pulmonary conditions are only available for a small percentage of the client population (Brooks et al 1999, 2007). Despite the relatively low uptake, PR programs provided within the community and home setting have been demonstrated to be cost-effective, improve quality of life, and decrease the number of future hospital days for the patient (Glassman 1998; Chapman et al 2003). In addition to poor availability of PR services, Chapman and colleagues (2003) reported that primary care physicians under-diagnose COPD, and that despite having symptoms of dyspnea, clients in general are not being treated for early symptoms related to COPD. Chapman and colleagues (2003) also suggested that health care costs for COPD could be better controlled with early detection and prevention within the primary care setting, and that PR would reduce the demand on emergency rooms and acute care settings.

The important global public policy issue is that demand for health and rehabilitation services associated with COPD appears to be outstripping supply. The evidence seems to suggest that PR services has the potential to mediate demand for more resource-intense services such as those provided 
during an acute exacerbation necessitating an emergency visit or hospital admission. As noted by Alvarez (2006), Kunisaki and colleagues (2007), FitzGerald and colleagues (2007), and Mannimo and Braman (2007), early intervention and PR program improve client and system-wide outcomes. Although the argument to include PR services as part of a comprehensive program has an evidence-based rationale, this reality does not easily translate into a decision-making or policy-making framework. We have argued elsewhere that the use of evidence at the policy level is infinitely more complex, and that evidence must be interpreted within context of prevailing values and other political pressures (Landry et al 2004). Based on rapidly increasing rates of COPD, we signal the need to reflect health reform strategies, such as integrating rehabilitation, health promotion and prevention, as costeffective approaches to mediate demand for growing demand for health services related COPD in a global environment of economic scarcity. Although implementing PR programs requires some degree of initial investment, it has the potential to yield important social and aggregated financial costs savings in a health arena of global consequence.

\section{Disclosure}

The authors declare no conflicts of interest in this work.

\section{References}

Ait-Khaled N, Enarson DA, Ottmani S, et al. 2007. Chronic airflow limitation in developing countries: burden and priorities. Int J Chron Obstruct Pulmon Dis, 2:141-50.

[ATS/ERS] American Thoracic Society/European Respiratory Society. 2002. ATS/ERS Statement on respiratory muscle testing. Am J Respir Crit Care Med, 166:518-624.

Alvarez HJ. 2006. [Global therapeutic approach of muscle dysfunction in COPD.] Nutr Hosp 21(Suppl 3):76-83.

[APCOPD] Asia Pacific COPD Working Group. 2005. Global initiative for Chronic Obstructive Lung Disease strategy for the diagnosis, management and prevention of chronic obstructive pulmonary disease: an Asia-Pacific perspective. Respirology, 10:9-17.

Barr RG, Celli BR, Martinez FJ, et al. 2005. Physician and patient perceptions on COPD: the COPD Resource Network Needs Assessment Survey. Am J Med, 118(12):1415.

Bousquet J, Ndiaye M, Ait-Khaled N, et al. 2003. Management of chronic respiratory and allergic diseases in developing countries. Focus on sub-Saharan Africa. Allergy, 58:265-83.

Brooks D, Sottana R, Bell B, et al. 2007. Characterization of pulmonary rehabilitation programs in Canada in 2005. Can Respir J, 14:87-92.

Brooks D, Lacasse Y, Goldstein RS. 1999. Pulmonary rehabilitation programs in Canada: national survey. Can Respir J, 6:55-63.

[CIHI] Canadian Institute for Health Information. 2005. Inpatient Rehabilitation in Canada 2003-2004. National Rehabilitation Reporting System [online]. Accessed on July 12 2007. URL: http://www.cihi.ca.

Carli F, Zavorsky GS. 2005. Optimizing functional exercise capacity in the elderly surgical population. Curr Opin Clin Nutr Metab Care, 8:23-32.

Cao Z, Ong KC, Eng P, et al. 2006. Frequent hospital readmissions for acute exacerbation of COPD and their associated factors. Respirology, $11: 188-95$
Chan-Yeung M, Ait-Khaled N, White N, et al. 2004a. Management of chronic obstructive pulmonary disease in Asia and Africa. Int J Tuberc Lung Dis, 8:159-70.

Chan-Yeung M, Ait-Khaled N, White N, et al. 2004b. The burden and impact of COPD in Asia and Africa. Int J Tuberc Lung Dis, 8:2-14.

Chapman KR, Bourbeau J, Rance L. 2003. The burden of COPD in Canada: results from the Confronting COPD survey. Respir Med, 97:23-31.

Chernew M. 2001. General equilibrium and marketability in the health care industry. J Health Polit Policy Law, 26:885-97.

Crockett AJ, Price D. 2007. Co-morbid disease in COPD - more than a coincidence. Int J Chron Obstruct Pulmon Dis, 2:339-401.

Fabbri LM, Boschetto P, Mapp CE; Global Initiative for Chronic Obstructive Lung Disease. Global Initiative for Asthma Management and Prevention. 2007. COPD guidelines: the important thing is not to stop questioning. Am J Respir Crit Care Med, 176:527-8.

Faulkner MA, Hilleman DE. 2002. The economic impact of chronic obstructive pulmonary disease. Exp Opin Pharmacol, 3:219-28.

Firlei N, Bernd L, Lea S, et al. 2007. [Die Pravalenz der COPD in Osterreich die erwartete Entwicklung bis 2020.] Weiner klinische Wochenschrift, 119(17-18):513-18.

FitzGerald JM, Haddon JM, Bradley-Kennedy C, et al. 2007. Resource use study in COPD (RUSIC): a prospective study to quantify the effects of COPD exacerbations on health care resource use among COPD patients. Can Respir J, 14:145-52.

Friedman B, Elixhauser A. 1995. The changing distribution of a major surgical procedure across hospitals: Were supply shifts and disequilibrium important? Health Econ, 4:301-14.

Gadoury MA, Schwartzman K, Rouleau M, et al. 2005. Self-management reduces both short-and long-term hospitalization in COPD. Eur Respir J 26:853-7.

Glassman SJ. 1998. Pulmonary rehabilitation in the acute inpatient rehabilitation hospital. Respir Care Clin N Am, 4:47-57.

Han MK, Postma D, Mannino DW, et al. 2007. Gender and chronic obstructive pulmonary disease. Am J Respir Crit Care Med, 176:1179-84.

Kida K, Jinno S, Nomura K, et al. 1998. Pulmonary rehabilitation program survey in North America, Europe, and Tokyo. J Cardiopulm Rehabil, 18:301-8.

Kunisaki KM, Rice KL, Niewoehner DE. 2007. Management of acute exacerbations of chronic obstructive pulmonary disease in the elderly: an appraisal of published evidence. Drugs Aging, 24:303-24.

Lacasse Y, Goldstein R, Lasserson TJ, et al. 2006. Pulmonary rehabilitation for chronic obstructive pulmonary disease. Cochrane Database Syst Rev, 4:CD003793.

Landry MD, Williams AP, Deber RB, et al. 2004. On evidence-based decision-making: Implications for physical therapy in the post-Kirby, post-Romanow era. Physiotherapy Canada, 56:7-12.

Landry MD, Jaglal S, Wodchis WP, et al. 2008. Analysis of factors affecting demand for rehabilitation services in Ontario, Canada: A health policy perspective. Disabil Rehabil, DOI: 10.1080/09638280701688078.

Landry MD, Williams AP, Verrier M, et al. 2007. Shifting the publicprivate mix: A policy analysis of physical therapy funding in Ontario. Physiotherapy Canada, 59:255-65.

Marcinkowski K, Wong VG, Dignam D. 2005. Getting back to the future: a grounded theory study of the patient perspective of total knee joint arthroplasty. Orthop Nurs, 24:202-9.

Mannimo DM, Braman S. 2007. The epidemiology and economics of chronic obstructive pulmonary disease. Proc Am Thoac Soc, 4:502-6.

Ninot G, Fortes M, Poulain M, et al. 2006. Gender differences in coping strategies among patients enrolled in an inpatient rehabilitation program. Heart Lung, 35:130-6.

O’Donnell DE, Hernandez P, Aaron S, et al. 2003. Canadian Thoracic Society COPD guidelines: summary of highlights for family doctors. Can Respir J, 10:463-6.

Prouty A, Cooper M, Thomas P, et al. 2006. Multidisciplinary patient education for total joint replacement surgery patients. Orthop Nurs, 25:257-61. 
Tatlicioglu T. 2007. Chronic obstructive pulmonary (COPD) disease and its future. Tuberkuloz ve Toraks, 55:303-18.

Varkey AB. 2004. Chronic obstructive pulmonary disease in women: exploring gender differences. Curr Opin Pulmon Med, 10:98-1003.

Viegi G, Pistelli F, Sherril DL, et al. 2007. Definition, epidemiology and natural history of COPD. Eur Respir J, 30:993-1013.

Wilkinson T, Wedzicha JA. 2006. Strategies for improving outcomes of COPD exacerbations. Int J Chron Obstruct Pulmon Dis, 1:335-42.
Wilson I. 2006. Depression in the patient with COPD. Int J Chron Obstruct Pulmon Dis, 1:61-4.

Yohannes AM, Connolly MJ. 2004. Pulmonary rehabilitation programmes in the UK: a national representative survey. Clin Rehabil, 18:444-9.

Zhong N, Wang C, Yao W, et al. 2007. Prevalence of chronic obstructive pulmonary disease in China: A large, population-based survey. Am J Respir Crit Care Med, 176:753-60. 